\title{
OBSERVATIONS ON 500 CASES OF MIGRAINE AND ALLIED VASCULAR HEADACHE
}

BY

\author{
GEORGE SELBY and JAMES W. LANCE
}

From the Northcott Neurological Centre, Sydney, Australia

Headache is probably the most common complaint referred to the neurologist for investigation. Approximately $12 \%$ of all patients seen at the Northcott Neurological Centre during the past six years were found to suffer from vascular headaches. At this Centre facilities for investigation are available without involving the patient in additional expense so that clinical observations are supported in most cases by electroencephalographic and radiological examinations.

The exact definition of the migraine syndrome is difficult and debatable and not all the patients in this series would fall within the narrow concept of a paroxysmal disturbance of cerebral function associated with unilateral headache and vomiting. The term "migraine" might reasonably be restricted to a disorder consisting of two separate phases, intracranial vasoconstriction, accompanied or followed by dilatation of the extracranial vessels. Clinical experience has shown, however, that the same patient may have attacks produced by either phase singly as well as in combination. While the term migraine is derived from "hemicrania", it is not unusual for patients to experience pain over the entire head with the same accompaniments as in their unilateral attacks. The essential characteristic of all these vascular headaches is their paroxysmal nature, and Gowers (1888) pointed out that the same patients may have simple headaches at one period of their life and the more complex series of symptoms at another period.

"The simple headaches have the same characters, and occur under the same causal conditions of heredity, etc., as those in which there are in addition other sensory symptoms."

The experimental studies of Wolff and his colleagues (Wolff, 1948, 1955) have established the similarity of the patho-physiological mechanism underlying migraine and other extracranial vascular headaches. The cases presented in this series come within this wider concept.

\section{Aetiological Factors}

Sex Incidence.-Our series comprises 300 females and 200 males. This female preponderance of $60 \%$ is slightly lower than the figure quoted by Kinniel Wilson (1940) who summarized 13 published series with a total of 3.278 cases and found that $71.6 \%$ were female.

Age of Onset.-The age at which the first attack occurred in 496 cases is shown in Fig. 1. The figure of $21 \%$ beginning under the age of 10 years is a little less than Gowers estimate of one-third and that of Balyeat and Rinkel (1931), who found an onset in the first decade in $30 \%$ of their 202 cases. Krayenbühl and Heyck (1955), on the other hand, state that only $12 \%$ of their 170 cases started in the first decade.

The first four decades account for $92 \%$ in our series. The youngest age reported for the first

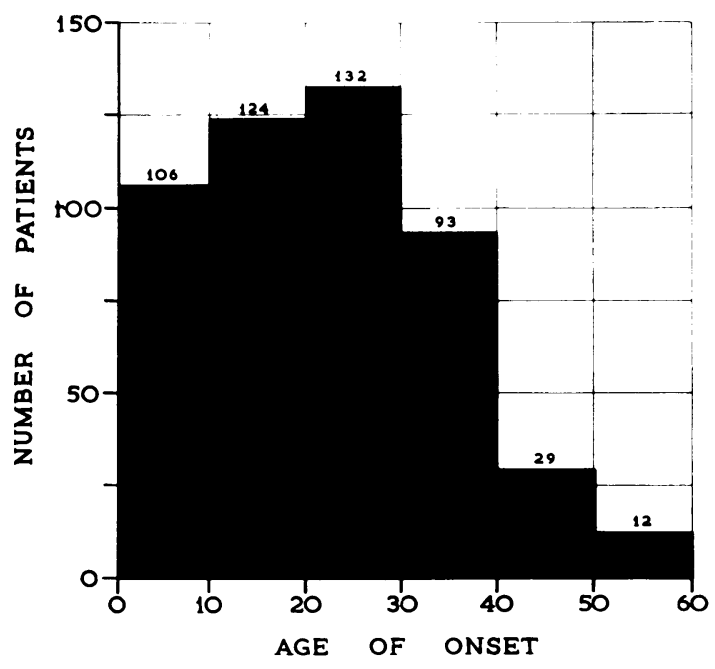

Fig. 1.-Diagram of the age at which the first migraine attack occurred. 
attack was 18 months, while at the other extreme one patient claimed to have suffered his first attack at the age of 60 years.

Family History.-Parents, grandparents and siblings of the patient were considered (Table 1).

TABLE I

FAMILY AND PERSONAL BACKGROUND OF MIGRAINEURS

\begin{tabular}{|c|c|c|c|}
\hline & & $\begin{array}{l}\text { No. of } \\
\text { Cases }\end{array}$ & $\begin{array}{c}\% \\
\text { Affected }\end{array}$ \\
\hline $\begin{array}{l}\text { Family } \\
\text { History }\end{array}$ & $\begin{array}{l}\text { Migraine } \\
\text { Epilepsy } \\
\text { Allergy }\end{array}$ & $\begin{array}{l}464 \\
439 \\
330\end{array}$ & $\begin{array}{l}55 \\
15 \\
38\end{array}$ \\
\hline $\begin{array}{l}\text { Past } \\
\text { Health }\end{array}$ & $\begin{array}{l}\text { Convulsions } \\
\text { Allergy } \\
\text { Recurrent vomiting attacks } \\
\text { "Biliousness" and motion sickness }\end{array}$ & $\begin{array}{l}348 \\
311 \\
198 \\
139\end{array}$ & $\begin{array}{l}11 \\
35 \\
31 \\
59\end{array}$ \\
\hline
\end{tabular}

Only definite positive and negative statements from the case history are included in this analysis and in those presented later. As suitable data had not always been obtained from all 500 cases, each figure is given as a percentage and the total number of patients from which this is calculated is shown.

A positive family history of migraine-type headaches was obtained in $55 \%$ of 464 patients. This agrees well with Lennox (1947) who gives a figure of $61 \%$ and Bassoe (1933) who reports a $57 \%$ incidence of parental migraine. Allan (1928) claims $91.4 \%$ of parental migraine in a series of 382 patients, but as the same author alleges that the incidence of migraine in the general population amounts to $60 \%$, his figure may be treated with reserve. Ely (1930) considered that $71 \%$ of "migraineurs" and 17\% of normal individuals had a migrainous family background.

Fifteen per cent of 439 patients in our series gave a family history of epilepsy. This is higher than the $5.7 \%$ mentioned by Ely (1930) and the $8.8 \%$ of Heyck (1956) and Flatau's figure of $7.2 \%$, but lower than the $20 \%$ of Ulrich. (The latter two authors are quoted from Kinnier Wilson.) Lennox (1946) states that about $4 \%$ of normal people have a known relative with seizures, and that epilepsy occurred in the relatives of migraineurs 3.6 times more often than in a control group.

An allergic diathesis was found in the family history of $38 \%$ of 330 of our patients. The leading questions to the patient specifically mentioned asthma, hay fever, and hives, but allergic dermatitis or eczema were included if mentioned.

Balyeat and Brittain (1930) quote a family history of allergy in 47 of 55 migraine patients, whereas Krayenbühl and Heyck (1955) found a positive family history in only six out of 60 cases.
Past Health.-A personal history of convulsions in childhood or epilepsy not directly associated with the migraine attack occurred in $11 \%$ of 348 of our subjects. Lennox (1947) records that seizures occur in approximately $5 \%$ of all children under the age of 5 . Considered together with the family history of epilepsy reported above as $15 \%$, our figures lend support to the belief in an association between these two paroxysmal maladies.

Thirty-five per cent. of 311 patients gave a past history of allergic disorders. This is higher than the incidence of allergic manifestations in the general population, which is regarded as $5-10 \%$ (Schwartz, 1953), and agrees with the general belief in allergy as a contributing factor in the aetiology of migraine. Kallós and Kallós-Deffner (1955) in a critical paper report 28 of 185 migrainous patients who had associated allergic disorders where exposure to a specific allergen always produced a typical migrainous attack at the same time as asthma, hay fever, or angioneurotic oedema. One patient in the present series appeared to have migraine as a reaction to a specific allergen.

Case 1.-A man of 46 with a family history of allergy but not migraine, and a past history of hay fever, had attacks of severe and persistently right-sided headaches, accompanied by nausea, photophobia, teichopsia, and scalp tenderness occurring daily each year in July from 1938 to 1949 . He then remained free from headaches until July, 1954, when he again had daily attacks.

From 1949 to 1954 he lived in Perth and Adelaide in the city, but in 1954 he returned to the Sydney suburb in which he had lived before 1949, with wattle trees in the vicinity of his home. The incidence of his attacks in July coincided with wattle blossom to which he is intensely allergic. The migraine responded dramatically to ergotamine tartrate.

The association of migraine with a history of cyclical vomiting in childhood is well recognized. Our enquiry extended beyond the strict definition of cyclical vomiting and of 198 cases $31 \%$ recalled frequently recurring bilious attacks. Of a further 139 patients, $59 \%$ gave a history of some bilious attacks or severe motion sickness during their early years.

Vahlquist and Hackzell (1949) reported a series of 31 children in whom the onset of migraine occurred between the ages of 1 and 4, and three of these had associated attacks of cyclical vomiting. Smith (1937) showed that of 55 children with cyclical vomiting, 50 had a family history of migraine, and 11 later developed this disorder. He mentions that nine out of 36 adult migraineurs had recurrent vomiting attacks in childhood. We have not been able to find adequate figures for the incidence of such attacks in the normal population, but it is of interest that 


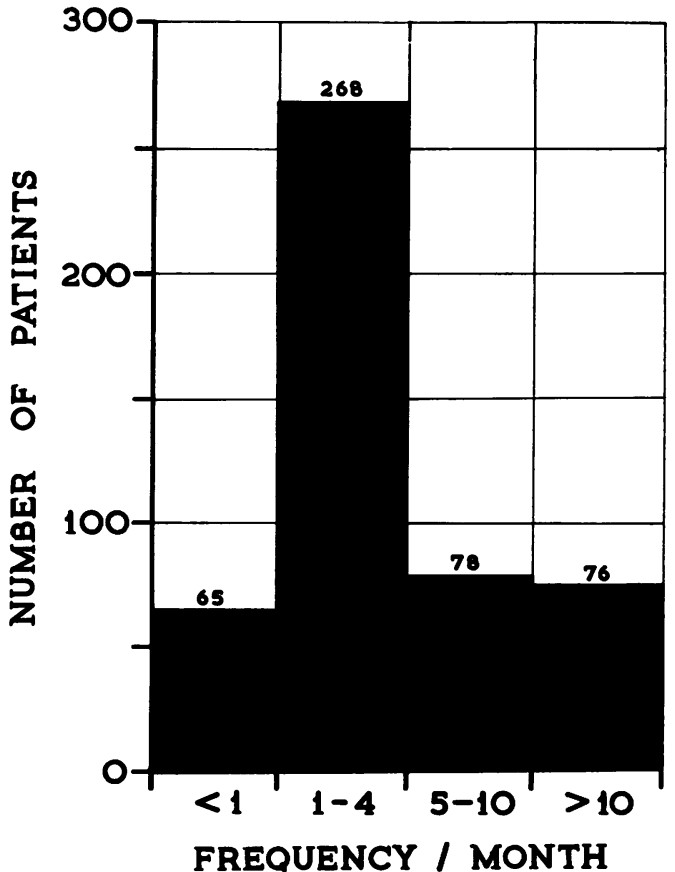

FIG. 2.-Diagram showing the incidence of attacks.

Smith (1951) asked 700 new boys at Rugby School about a past history of bilious attacks, and $198(18 \%)$ replied that they had suffered such attacks "occasionally, sometimes, or often".

\section{Clinical Features}

Frequency of Attacks. - The average number of attacks of headache per month in 487 patients is shown in Fig. 2. This indicates that more than one half of the patients experienced from one to four episodes each month. Averages are, however, difficult to compute with any degree of accuracy as the distribution may vary widely from year to year in an individual patient. It was our impression that emotional factors became of greater aetiological significance as the frequency of attacks increased. In the $15 \%$ of patients who reported more than 10 attacks each month, tension headaches often occurred in addition to migraine and the patient may not always have been able to differentiate the two.

Precipitating Factors.-Physiological and environmental factors which the patients had recognized as triggers for their attacks are shown in Table II. The cause of the common association between migraine and the menstrual cycle remains
TABLE II

FACTORS PRECIPITATING THE MIGRAINE ATTACK

\begin{tabular}{l|c|c}
\hline \multicolumn{1}{c|}{ Precipitating Factor } & No. of Cases & \% Affected \\
\hline Menses & 196 & 62 \\
Emotion & 388 & 67 \\
Glare & 293 & 47 \\
Foods & 339 & 25 \\
\hline
\end{tabular}

uncertain but hormonal changes, fluid balance, and nervous tension may all play a part. About twothirds of patients were aware of the causal importance of emotional upsets. These may be of minor nature such as a shopping expedition among city crowds, or a major domestic upheaval. Patients described as being susceptible to glare include those who experienced attacks after exposure to the flicker of moving pictures or television.

Fats, fried foods, chocolates, and oranges were most often incriminated as causal dietary factors. Tomatoes, pineapples, and onions were occasionally mentioned. Alcoholic drinks were not included in this part of the survey, as vasodilatation is the probable mechanism of headache following alcohol, rather than idiosyncrasy to a food.

Duration of Attacks. - It can be seen from Fig. 3 that the headache persisted for less than a day in about two-thirds of patients.

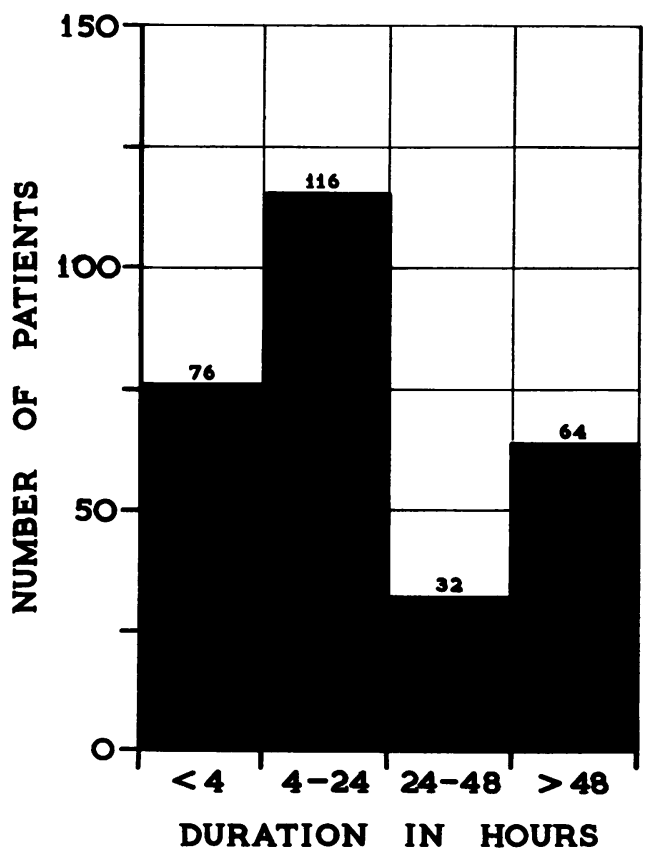

Fig. 3.-Diagram showing the duration of the migraine attack. 
Site of Headache.-This was recorded in all 500 cases (Table III). In 190 patients all attacks were

TABLE III

SITE OF HEADACHE

\begin{tabular}{ccc|c}
\hline Hemicrania only: & & \\
Same side & $\ldots$ & 103 & \\
Either side & $\cdots$ & 87 & 190 \\
Holocrania only & & & 191 \\
Mixed forms & 113 \\
Migraine equivalents & & 6 \\
Total number of cases & & 500 \\
\hline
\end{tabular}

hemicranial. In 87 of these either side of the head might be involved, while in the remaining 103 patients the pain invariably affected the same side of the head. This latter figure, representing $21 \%$ of the whole series, is of interest in view of the widely held belief that a hemicrania persistently confined to the same side may indicate an underlying intracranial lesion. Seven of these patients were submitted to angiography but no abnormality was demonstrated.

A further 113 patients had attacks of hemicrania which were either followed by, or alternated with, generalized headaches. These will be referred to as "mixed forms" later in this paper.

One hundred and ninety-one patients $(38 \%)$ reported pain over the entire head in all their attacks. It seems appropriate to refer to these as "holocrania" (Gk. holos $=$ whole). Their inclusion in this series was justified by the associated clinical features to be discussed. Critchley and Ferguson (1933) estimated that possibly as many as $50 \%$ of migraineurs experience bilateral headache, and our figure of $38 \%$ approaches this.

Headache was not a symptom of the attack in six patients. Two had suffered typical migraine in their earlier years and recognized their remaining periodic complaints as part of a migraine attack. Their symptoms were mainly visual including fortification spectra and hemianopia. Two had transient paraesthesiae, and one was regarded as "retinal migraine". Two case histories follow to illustrate these points.

Case 2.-A case of "retinal migraine": a flying instructor, aged 33, without a family history of migraine, developed attacks which started with a "starry feeling" in front of the left eye. He then saw bright lights "like silver paper" which lasted for $\mathbf{3 0}$ seconds approximately. Vision was then partially or completely lost in the left eye for a period of five minutes, and the left pupil was dilated during this time. The amblyopia then resolved leaving a dull ache behind the left eye. He had suffered six attacks in the past eight months when first seen, and has had two in the 16 months since. A plain radiograph of the skull, an E.E.G., and a left carotid angiogram were normal.
Case 3.-A case of migraine equivalent: a university lecturer and statistician, aged 52, with a family history of convulsions, migraine, and allergy, suffered from attacks of classical migraine from the ages of 17 to 23 . He was then free from all symptoms for 10 years, but at the age of 33 a new symptom complex appeared without headaches. The attack would begin with sudden blurring of vision for three or four minutes followed by distressing sensations of circles, lines, and zig-zags dancing in front of his eyes for some $\mathbf{3 0}$ minutes after which the attack ceased, leaving him exhausted. Frequently there was accompanying nausea, photophobia, and giddiness. All efforts at treatment with ergotamine, histamine, and sedatives failed. Amyl nitrite and nicotinic acid brought no relief but "ronicol" has recently reduced their frequency.

Accompanying Symptoms.-Symptoms commonly associated with the attack of headache are shown in Table IV. While nausea was a complaint of the

TABLE IV

SYMPTOMS ASSOCIATED WITH MIGRAINE ATTACK

\begin{tabular}{l|c|c}
\hline \multicolumn{1}{c|}{ Symptom } & No. of Cases & $\%$ Affected \\
\cline { 2 - 3 } Nausea & 491 & 87 \\
Vomiting & 483 & 56 \\
Photophobia & 435 & 82 \\
Visual disturbances & 448 & 41 \\
Paraesthesiae & 395 & 33 \\
"Dizziness" & 131 & 72 \\
Vertigo & 217 & 33 \\
"Blackouts" & 396 & $18 \cdot 5$ \\
$\quad$ Epilepsy & - & $4 \cdot 5$ \\
Syncope & - & $10 \cdot 5$ \\
Confusional state & - & $3 \cdot 5$ \\
Scalp tenderness & 317 & 65 \\
\hline
\end{tabular}

great majority of patients, vomiting occurred in little more than half. Photophobia is a common feature of the migraine attack yet we know very little about the mechanism producing this symptom. Persistent mild photophobia is a symptom of tension headache, in which the conjunctival vessels are constricted (Ostfeld, Reis, and Wolff, 1957), and acute photophobia is a common feature of migraine headache, in which these vessels are dilated. Eckardt, McLean, and Goodell (1943) showed that photophobia occurred when various irritants were applied within the territory of the ophthalmic division of the trigeminal nerve, and that this effect was independent of conjunctival vasodilatation. They concluded that photophobia was a form of referred pain.

The heading "visual disturbances" includes spots, flashes, and circles before the eyes as well as fortification spectra and various transient defects of the visual field. Simple blurring of vision as the sole visual phenomenon is almost universal and not included in this analysis.

Paraesthesiae are of course part of the phase of intracranial vasoconstriction and may occur on the 
same side as the subsequent headache or be contralateral. Visual and sensory phenomena have been attributed in the past to vasoconstriction alone but the slow "march" of symptoms and their usual duration of 20 to 30 minutes suggests that some other factor of cerebral suppression may be involved as well. Milner (1958) points out that the condition of "spreading depression" in cerebral pbysiology, described by Leão (1944), has similar time relations to these clinical symptoms.

Some $72 \%$ of 131 patients complained of a sensation of dizziness, light-headedness, and unsteadiness, usually aggravated by stooping and rising, and apparently an expression of the vasomotor instability which is a common characteristic of migraineurs. True vertigo within the definition of hallucination of movement was experienced by $33 \%$ of a further 217 patients. In addition to this series we have seen several women who developed attacks characteristic of labyrinthine vertigo after the menopause with a history of classical migraine during their youth. It is possible that in these patients the angiospastic tendency has become confined to the vestibular end-arteries.

Sixty patients of 396 had lost consciousness in association with attacks of headache. The description of the "blackout" suggested an epileptic seizure in 18 of these, and a syncopal attack in the remaining 42. A family history of epilepsy was available in four of 17 of the patients with epileptic attacks, and a past history of seizures in seven out of 13 . The incidence of $4.5 \%$ of epilepsy occurring in relation to migraine attacks further supports the thought of kinship between these two disorders. A further 14 patients commented on mental confusion without loss of consciousness as a feature of their migraine. Some of these had severe impairment of mental faculties such as automatisms and apparently hysterical behaviour occurring at the height of the headache.

Case 4.-A woman of 21 , whose family background was free of headaches and epilepsy, had been subject to migraine from the age of 10 . The attacks occurred once or twice a week and started with "spots in front of the eyes" in both halves of the visual field. Everything appeared "as though seen through a sheet of rippling water". Headache then started over the right eye and spread to become bilateral, lasting about one hour. When the headache was at its height she became confused and once walked out of the house, forgetting all about her children. On another occasion she was found banging her head on the wall repeatedly. At the age of 19 she started to have grand mal fits about once every three months. Each attack began with a feeling as though her head were rotating around to the left, then she saw "a wall of water" appear on the left side before losing consciousness. Physical examination and a radiograph of the skull were negative, but her E.E.G. showed brief paroxysms of wave and spike, at 4-5 c.p.s.

This case is of particular interest in that a similar visual symptom preceded both migraine and epilepsy, and that the E.E.G. was indicative of centrencephalic discharge.

Tenderness of the scalp during or after the headache was experienced by some two-thirds of our patients. This may be so severe as to prevent the patient from lying on the affected side, or described only as abnormal sensitivity when combing or brushing the hair. This tenderness may involve any part of the scalp, face, or nuchal region, and cannot be correlated with either trigeminal or cervical radicular distribution. The widespread distension of the extracranial blood vessels or spasm of the suboccipital and scalp muscles would reasonably explain this symptom, and the latter would account for its occurrence also in tension headaches. Hughes and Cooper (1956) drew attention to the frequency of tenderness over the tip of the first cervical transverse process in headaches during childhood and discussed possible mechanisms.

Personality.-Our assessment of the patients. personality structure (Table V) is based on simple

TABLE V

PERSONALITY STRUCTURE IN 500 CASES OF MIGRAINE

\begin{tabular}{ll}
\hline Obsessional trends & $23 \%$ \\
Tenseness, hyperactivity & $22 \%$ \\
Anxiety state & $13 \%$ \\
"Normal" & $\mathbf{4 2} \%$ \\
\hline
\end{tabular}

questions about their habits, reactions to stress, and tendency to check simple things or to brood over trifles. A more thorough psychiatric evaluation was obtained in a few instances.

In $23 \%$ definite obsessional trends were recorded in the history but this figure should probably be higher as specific details of the patients' personality were not available in all instances. These patients admitted to being overconscientious, unduly tidy, or house proud and were in the habit of doublechecking their actions. Another $22 \%$ were hyperactive individuals, with minor psychosomatic symptoms of nervous tension. These were restless people, unable to relax, but without more definite manifestations of an anxiety reaction. A further $13 \%$ had overt symptoms of an anxiety state including digital tremors, nervous dyspepsia, insomnia, and a tendency to overbreathe, in addition to headache. Some patients in this and the preceding group had tension headaches as well as periodic migrainous episodes. A feeling of depression is not unusual after the migraine attack and 19 of the patients with 
anxiety states confessed to more prolonged episodes of depression unconnected with the headache. It must be stressed that the first two groups of people with obsessional or overactive temperaments refer only to a personality type without implying an emotional disorder. If a more detailed analysis had been possible, it is likely that some of the $42 \%$ of our series classified as "normal" would have fallen into either obsessional or hyperactive groups.

Physical Signs.-A complete neurological examination was carried out on each patient. In a few cases alteration in muscle tone, and asymmetry of reflexes were found. If these persisted on repeated examination, further neuroradiological investigations were undertaken to exclude an organic lesion.

In 10 cases an intracranial bruit was audible on auscultation over the orbits. Two of these were children under the age of 10 years in whom this sign is not usually of significance. In four adult patients the bruit was heard over both eyes, and in the remaining four it was unilateral. Carotid angiograms were performed in three of the latter and all were normal.

It is generally agreed that moderate hypertension alone does not cause headache though it may aggravate a previous disposition to migraine. It is worthy of note that the blood pressure on routine examination exceeded $150 \mathrm{~mm}$. $\mathrm{Hg}$ systolic and $100 \mathrm{~mm}$. $\mathrm{Hg}$ diastolic in only $13 \%$ of our 500 cases.

Radiological Findings.-A plain radiograph of the skull was taken in 453 of the 500 cases. Hyperostosis frontalis interna was found in 17 cases and hyperostosis calvaria diffusa in five. Localized areas of translucency, possibly epidermoids, occurred in three, sinus infection in two, osteoma of a frontal sinus in two, old fractures in two, and metallic foreign bodies resulting from an old shrapnel war wound were found in one patient. In only four cases were the appearances suggestive of an intracranial lesion. In one patient with left-sided headaches and a flattened left clinoid process, an angiogram was normal. Another patient, with a persistent right-sided headache and a bruit audible over the right eye, showed some sclerosis around the right optic foramen and again the carotid angiogram was normal. One patient had calcification in the right parieto-occipital region with a normal E.E.G. and normal carotid angiogram. In another patient calcification was noted in the suprapituitary region, but as there was no defect in the visual fields, no further examination was carried out.

Seventeen patients in all had carotid angiograms performed, three because of a persistent E.E.G. focus, three with a suspicious plain radiograph, two with ophthalmic migraine, two for hemiparesis accompanying attacks, one for partial Jacksonian fits not always related to headache, and one solely for unilateral bruit. The remaining five had persistent severe unilateral headaches. All these carotid angiograms were normal.

The relationship of migrainous headaches to intracranial angiomas is still in doubt, and this relationship has only been found in one of our patients, who is not included in this series.

Case 5.-A man of 34 years with a negative family history of migraine, suffered a subarachnoid haemorrhage at the age of 24 years. Carotid angiography showed a right parieto-occipital angioma for which he refused surgery. He remained free of symptoms for two years after the intracranial haemorrhage and then developed periodic attacks of photopsia in the form of coloured balls and stars followed by transient left hemianopia and a severe generalized headache accompanied by nausea which was always relieved by dihydroergotamine taken by mouth.

E.E.G. Findings. - To the best of our knowledge there have been only few reported observations on the electroencephalogram in adequate numbers of migraine patients. Dow and Whitty (1947) found 30 abnormal records in 51 patients. Twenty-six of these had diffuse or paroxysmal slow wave changes, and in four focal abnormalities were recorded. Air studies in three of the latter patients showed a normal ventricular system.

Ulett, Evans, and O'Leary (1952) described the findings in 1,000 patients with the chief complaint of headache. They do not pay specific attention to migraine and their criteria of an abnormal record include fast activity occurring during $40 \%$ of the record, as well as slow activity of less than 7 c.p.s. exceeding 50 microvolts, and paroxysmal records. Of their 1,000 cases, $15.8 \%$ were considered to have abnormal records. Three hundred and ten of their patients had hemicrania and in $13.2 \%$ of these the E.E.G. was abnormal. If vomiting accompanied the headache, the proportion of abnormal records increased to $18 \%$, and a similar percentage was found in patients with a family history of headache or epilepsy.

Heyck (1956) reported 80 E.E.G.s in 62 migraine sufferers. Twelve of these patients showed hypersynchrony, and a further 13 non-specific diffuse slow wave dysrhythmias. Five patients showed focal abnormalities between attacks and all these had focal symptoms accompanying the attacks. Disregarding the hypersynchronies, $29.1 \%$ of his series had abnormal records. He adds a further series of 200 patients with extracranial vascular headaches of whom $12.5 \%$ had diffuse slow wave changes and $6 \%$ focal abnormalities. 
Electroencephalograms were recorded in 459 of our patients (Table VI). No specific attention was

TABLE VI

E.E.G. RECORDS IN 459 CASES OF MIGRAINE

\begin{tabular}{lr|c}
\hline Normal records & $53 \cdot 7 \%$ & Within normal limits \\
Excessive fast activity & $16.5 \%$ & $70 \cdot 2 \%$ \\
\hline Excessive slow activity & $26.2 \%$ & Abnormal records \\
Asymmetrical slow activity & $3.2 \%$ & $29.8 \%$ \\
Wave and spike paroxysms & $0.4 \%$ & \\
\hline
\end{tabular}

paid to hypersynchrony nor rigid criteria laid down for abnormal tracings. The 4-7 c.p.s. activity, persistent or occurring in runs, was regarded as being beyond the range of normal in $122(26 \%)$. Fifteen cases $(3 \%)$ showed lateralizing abnormalities, usually in one temporal region. Carotid angiograms on three of these patients were normal. Wave and spike paroxysms were found in two cases. In one of these the frequency was 4-5 c.p.s. and this patient, who suffered also from epilepsy, is reported in detail above (Case 4). In the other case, the frequency was 3 c.p.s., yet the patient had neither a personal nor family history of epilepsy.

In 77 patients $(16.5 \%)$ fast activity in the beta range was considered to be more prominent than usual. If these are included among normal records, 139 of our 459 patients or approximately $30 \%$ had abnormal tracings. This figure agrees fairly closely with Heyck.

In 74 patients who experienced impairment of consciousness with their headaches, the E.E.G. was abnormal in $40 \%$. Only 18 of these had definite epileptic seizures as a part of the attack, and of these seven had abnormal interictal tracings.

From generally accepted criteria, less than $15 \%$ of the healthy adult population have dysrhythmic E.E.G. records. The incidence of $30 \%$ abnormalities in this and previous series would therefore be significant.

Ulett et al. (1952) commented that the percentage of disordered tracings in their 1,000 patients complaining of headache differed for the sexes, being $9.7 \%$ for males and $20.5 \%$ for females. We reviewed our series and found that $26 \%$ of males and $32 \%$ of females were considered to have abnormal records. Some degree of slow activity is physiological in children of 12 years and under, and criteria of abnormality are more difficult to establish than in the adult patient. We therefore studied our series again after the elimination of this young age group and found that 27 out of 149 males $(18 \%)$ and 78 of 260 females $(30 \%)$ were reported as having abnormal E.E.G.s. Thus if only patients of 13 years and over are considered, 105 out of 409 or $26 \%$ had abnormal records.

\section{Response to Treatment}

Ergotamine.-Ergotamine tartrate, either alone or in combination with caffeine, is universally accepted as the most effective drug in the treatment of vascular headaches. In our series $47 \%$ of 263 patients stated that their headache was rapidly abolished by the early administration of one of these preparations sublingually, orally, or by injection. A further $34 \%$ obtained partial relief, indicating that only some of their attacks were aborted or that headache of diminished severity continued. Nineteen per cent. considered that these drugs failed to alleviate their pain. These figures compare reasonably with a table of results in 1,070 cases reported from $21 \mathrm{ob}-$ servers by Vallery-Radot (1955). Of this combined series, $66.2 \%$ obtained excellent relief and a further $16.9 \%$ responded partially, while the remaining $16.9 \%$ derived no benefit. Various other figures quoted by the same author indicated an overall efficacy of ergotamine compounds in $80 \%$.

Considering the reluctance of some patients to take the drug during the early phase of the attack, the delay when injections have to be given, the emotional circumstances surrounding some attacks, the patients' fear of nausea and other sideeffects, and the development of drug resistance, an accurate statistical evaluation of the results of treatment is extremely difficult.

Histamine.-Intravenous histamine was given to 76 patients in three infusions at weekly intervals. Histamine acid phosphate was diluted in $250 \mathrm{ml}$. of normal saline in a dose of $1 \mathrm{mg}$. for the first, $1.5 \mathrm{mg}$. for the second, and $2 \mathrm{mg}$. for the third infusion. Each was given as a slow drip over a period of two hours.

The patient's response was considered as excellent if he remained free of attacks for a period of eight months or more, and $16(21 \%)$ came into this category. A good response implies a reduction in frequency of attacks to less than half the previous number; 32 patients $(42 \%)$ reported such a result. Another 13 patients $(17 \%)$ considered that the severity of their attacks had diminished but our records showed that their frequency remained unaltered. These were regarded as poor results. Twenty-one patients stated that the treatment had no effect, and two claimed to be worse after it. In summary, the treatment was considered to be of value in $63 \%$.

Patients selected for histamine therapy had either a strong personal history of allergic disorders, or had proved resistant to other forms of treatment.

On analysis the response to treatment showed no correlation with a positive personal or family history of allergic disorder. In the absence of valid controls 
it is impossible to say whether this treatment affects the psyche or the soma but we have noted with interest that the majority of patients who failed to respond had previously been considered as having a personality disorder.

TABLE VII

RESPONSE TO TREATMENT

\begin{tabular}{l|c|c|c|c}
\hline \multirow{2}{*}{ Treatment } & $\begin{array}{c}\text { Number } \\
\text { of } \\
\text { Cases }\end{array}$ & Excellent & Good & No Relief \\
\hline $\begin{array}{l}\text { Ergotamine } \\
\text { Histamine }\end{array}$ & 263 & $47 \%$ & $34 \%$ & $19 \%$ \\
\hline
\end{tabular}

\section{Definition of the Migraine Syndrome}

We have stated earlier that not all the patients in this series would fall within the narrow concept of a paroxysmal disturbance of cerebral function associated with unilateral headache and vomiting. We have therefore studied separately the clinical features of patients whose headache is habitually hemicrania or holocrania. Mixed forms are included with the hemicranial group as these headaches are unilateral for a considerable part of the attack. Each group has been further divided by distinguishing those complaining of focal cerebral symptoms associated with the headache. The case histories of 290 patients were analysed for this purpose, of which 101 experienced such focal phenomena.

Classical symptoms of major visual disturbance (teichopsia, hemianopia, or scotomata), paraesthesiae, or aphasia occurred in 59 of these patients, preceding the headache in 37 and appearing at the height of the headache in 22. Minor visual disorders such as spots, circles, and flashes in front of the eyes were noticed before the headache in 12, and concurrently with the headache in 30 . Generalized blurring of vision was not considered to be specific and a patient was not included in the "focal" group on this ground alone.

All figures presented in Tables VIII-X are based on definite statements in the case history as were the comparable tables concerning the whole series.

Table VIII compares the aetiological factors in the various groups. It will be seen that neither the family history nor the past health of these patients bears any relation to the situation of the headache or to the occurrence of focal cerebral disturbances.

In the analysis of precipitating circumstances (Table IX), the higher incidence of menstrual association and of food idiosyncrasy in patients with hemicrania is worthy of note.

The symptoms accompanying the headache (Table $\mathrm{X}$ ) occur with a remarkably similar frequency in all groups. Even visual disturbances and paraesthesiae, often considered as cardinal features of
TABLE VIII

COMPARISON OF AETIOLOGICAL FACTORS IN RELATION TO SITE OF HEADACHE AND ASSOCIATED SYMPTOMS

\begin{tabular}{|c|c|c|c|c|c|}
\hline & \multicolumn{2}{|c|}{ Hemicrania } & \multicolumn{2}{|c|}{ Holocrania } \\
\hline & & Focal & Non-focal & Focal & Non-focal \\
\hline \multicolumn{2}{|c|}{$\begin{array}{l}\text { Number of cases } \\
\text { Ratio female/male }\end{array}$} & $\stackrel{54}{1 \cdot 5}$ & 111 & $\begin{array}{l}47 \\
1 \cdot 2\end{array}$ & ${ }_{1 \cdot 0}^{78}$ \\
\hline $\begin{array}{l}\text { Family } \\
\text { History }\end{array}$ & $\begin{array}{l}\text { Migraine } \\
\text { Epilepsy } \\
\text { Allergy }\end{array}$ & $\begin{array}{l}45 \% \\
13 \% \\
30 \%\end{array}$ & $\begin{array}{l}53 \% \\
14 \% \\
32 \%\end{array}$ & $\begin{array}{l}50 \% \\
21 \% \\
20 \%\end{array}$ & $\begin{array}{l}52 \% \\
31 \%\end{array}$ \\
\hline $\begin{array}{l}\text { Past } \\
\text { History }\end{array}$ & $\begin{array}{l}\text { Epilepsy } \\
\text { Allergy } \\
\text { Recurrent } \\
\text { vomiting } \\
\text { attacks }\end{array}$ & $\begin{array}{l}22 \% \\
18 \% \\
34 \%\end{array}$ & $\begin{array}{l}57 \% \\
34 \% \\
34 \%\end{array}$ & $\begin{array}{l}13 \% \\
28 \% \\
30 \%\end{array}$ & $\begin{array}{l}15 \% \\
26 \% \\
26 \%\end{array}$ \\
\hline
\end{tabular}

TABLE IX

COMPARISON OF PRECIPITATING FACTORS

\begin{tabular}{l|c|c|c|c}
\hline \multicolumn{1}{c|}{$\begin{array}{c}\text { Precipitating } \\
\text { Factors }\end{array}$} & \multicolumn{2}{c|}{ Hemicrania } & \multicolumn{2}{c}{ Holocrania } \\
\cline { 2 - 5 } & Focal & Non-focal & Focal & Non-focal \\
\hline Emotion & $72 \%$ & $63 \%$ & $69 \%$ & $56 \%$ \\
Glare & $57 \%$ & $34 \%$ & $40 \%$ & $37 \%$ \\
Food & $43 \%$ & $19 \%$ & $19 \%$ & $12 \%$ \\
\hline Menses & $71 \%$ & $76 \%$ & $49 \%$ & $45 \%$ \\
\hline
\end{tabular}

TABLE $X$

COMPARISON OF ASSOCIATED SYMPTOMS

\begin{tabular}{|c|c|c|c|c|}
\hline \multirow{2}{*}{ Associated Symptoms } & \multicolumn{2}{|c|}{ Hemicrania } & \multicolumn{2}{|c|}{ Holocrania } \\
\hline & Focal & Non-focal & Focal & Non-foca \\
\hline $\begin{array}{l}\text { Nausea } \\
\text { Vomiting } \\
\text { Photophobia } \\
\text { Visual disturbances } \\
\text { Paraesthesiae } \\
\text { Vertigo } \\
\text { Blackouts } \\
\text { Scalp tenderness }\end{array}$ & $\begin{array}{l}87 \% \\
67 \% \\
87 \% \\
72 \% \\
53 \% \\
45 \% \\
24 \% \\
72 \%\end{array}$ & $\begin{array}{l}92 \% \\
69 \% \\
75 \% \\
0 \\
0 \\
28 \% \\
10 \% \\
60 \%\end{array}$ & $\begin{array}{l}86 \% \\
62 \% \\
79 \% \\
76 \% \\
58 \% \\
43 \% \\
30 \% \\
61 \%\end{array}$ & $\begin{array}{l}90 \% \\
54 \% \\
75 \% \\
0 \\
0 \\
30 \% \\
10 \% \\
46 \%\end{array}$ \\
\hline
\end{tabular}

migraine, occur with generalized headaches as frequently as with hemicrania. Vertigo and impairment of consciousness are rather more frequent in those patients subject to focal cerebral disturbances, suggesting that a common mechanism may produce these symptoms, whether it be intracranial vasoconstriction or spreading cerebral depression.

Personality disorder had the same distribution in each subgroup as that shown for the whole series in Table $\mathrm{V}$.

No significant difference could be found in the percentage of E.E.G. abnormality in the various groups.

The response to ergotamine compounds is shown in Table XI and is comparable for each division. The effect of histamine treatment was similar to that presented for the entire series but the numbers involved were too small to draw any definite conclusion.

The similarity of the clinical picture in the various groups indicates that there is no justification for 
TABLE XI

COMPARISON OF RESPONSE TO ERGOTAMINE

\begin{tabular}{l|c|c|c|c}
\hline $\begin{array}{c}\text { Response to Ergotamine } \\
\text { in 168 Cases }\end{array}$ & \multicolumn{2}{|c|}{ Hemicrania } & \multicolumn{2}{|c}{ Holocrania } \\
\cline { 2 - 3 } & Focal & Non-focal & Focal & Non-focal \\
\hline Excellent & $54 \%$ & $62 \%$ & $50 \%$ & $60 \%$ \\
Good & $23 \%$ & $23 \%$ & $25 \%$ & $24 \%$ \\
No relief & $23 \%$ & $15 \%$ & $25 \%$ & $16 \%$ \\
\hline
\end{tabular}

regarding "classical migraine" as an entity distinct from other forms of extracranial vascular headache. Differences in clinical presentation depend essentially on the degree of participation by the intracranial vessels.

\section{Discussion}

Since Liveing's monograph of 1873 there have been many contributions to the literature on migraine, often expressing personal opinion without statistical confirmation. Strong views favouring an allergic, a vascular, or a psychiatric aetiology have been expressed, usually depending on the particular interests of the author. As a result the widespread disturbance of physiological function in the migraine attack is usually neglected. The present paper was designed to assess some of the various aetiological and clinical features in a reasonably large number of patients.

From our results we reaffirm the generally held opinion that there is no single cause for vascular headache but that heredity and personality structure provide the common background with an allergic diathesis contributing in about one-third of cases. The association with epilepsy and abnormal electroencephalographic tracings indicates that cerebral dysrhythmia must be considered as one causative mechanism. General instability of the autonomic nervous system manifests itself from infancy in attacks of cyclical vomiting, proneness to travel sickness and fainting, and participates extensively in the actual migraine attack. The constriction of intracranial vessels and dilatation of extracranial vessels may be only facets of disturbed vasomotor control and we feel that this extends beyond the cranial circulation and involves the peripheral vasculature.

Changes in fluid balance must also be considered in any discussion on mechanisms underlying the migraine attack. Oliguria, which often precedes and accompanies the attack, and polyuria, which occurs as the attack subsides, are familiar features. Wolff (1955) records that 63 out of 134 patients gave such a history, and that in 31 out of 51 cases fluid retention was shown by weight measurement. However, headaches still occurred when fluid retention was prevented, and were not precipitated when fluid retention was induced artificially by injections of pitressin. They concluded that fluid retention and headache are concomitant phenomena which are not causally related. This does not exclude the possibility that these changes in fluid balance are an index of hypothalamic dysfunction which may have a part to play in the migraine attack in other ways.

The evidence so far available indicates that the migraine syndrome is basically a disturbance of autonomic regulation with the main impact on intracranial and extracranial arteries. The effect of psychological factors in triggering attacks is not surprising in view of the importance of the autonomic nervous system as the somatic mediator of the emotional state.

It remains a mystery why single intracranial vessels should be selectively involved, producing a recurrent pattern of cerebral disturbance which may be constant for a particular patient.

It is similarly of interest that in some patients the branches of the external carotid artery are not involved symmetrically, but that one side or even a single vessel may be exclusively affected. In this connexion the development of migrainous headache after traumatic contusion of an extracranial vessel, sometimes underlying a scalp laceration, may be relevant. As this occurs in a patient who has never before experienced headache, one might suspect that the periarterial sympathetic plexus has been damaged rendering the vessel more susceptible to painful dilatation. If such a contused vessel is surgically ligated the chances of curing the headache should be much better than in primary migraine, where experience has shown that headache frequently recurs in some other place after ligation of one extracranial vessel.

The migraine syndrome provides an interesting study for the clinician because of the diversity and severity of its symptoms. With further basic research, the time should be close when the many fragments of knowledge may be joined together into a single concept.

\section{Summary}

The aetiological factors, clinical features, and response to treatment are presented in a series of 500 patients suffering from extracranial vascular headache.

It is shown that there is no significant difference in the associated clinical phenomena whether the headache is hemicranial or of generalized distribution.

Impairment of consciousness was more common in patients in whom attacks were accompanied by other symptoms of cerebral dysfunction.

The E.E.G. findings in $\mathbf{4 5 9}$ patients are mentioned, and it is shown that approximately $30 \%$ of patients 
had abnormal records, irrespective of the association of focal cerebral disturbances with the headache. If only patients of 13 years and over were considered $26 \%$ were found to have abnormal records, the percentage being higher for female than for male patients.

Radiographs of the skull were available in $\mathbf{4 5 3}$ cases, and angiograms were performed on 17 patients in whom there was clinical suspicion of focal intracranial disease.

The pathogenesis of the migraine syndrome is discussed in terms of periodic autonomic instability and the selective susceptibility of individual cranial arteries.

We are indebted to Dr. L. R. Rail who reported on the electroencephalograms, and to our colleagues on the staff of the Northcott Neurological Centre who have permitted us to include some of their patients.

\section{REFERENCES}

Allan, W. (1928). Arch. intern. Med., 42, 590. Balyeat, R. M., and Brittain, F. L. (1930). Amer. J. med. Sci.,

-, and Rinkel, H. J. (1931). Amer. J. Dis. Child., 42, 1126.
Bassoe, P. (1933). J. Amer. med. Ass., 101, 599.

Critchley, M., and Ferguson, F. R. (1933). Lancet, 1, 123.

Dow, D. J., and Whitty, C. W. M. (1947). Ibid., 2, 52 .

Eckardt, L. B., McLean, J. M., and Goodell, H. (1943). Re s. Publ Ass. nerv. ment. Dis., 23, 209.

Ely, F. A. (1930). Arch. Neurol. Psychiat. (Chicago), 24, 943.

Gowers, W. R. (1888). A Manual of Diseases of the Nervous System.

Churchill, London.

Heyck, H. (1956). Neue Beiträge zur Klinik und Pathogenese der Migräne. Thieme, Stuttgart.

Hughes, E. L., and Cooper, C. E. (1956). Brit. med. J., 1, 1138.

Kallós, P., and Kallós-Deffner, L. (1955). Int. Arch..Allerg.v, 7,

Krayenbühl, H., and Heyck, H. (1955). Ibid., 7, 339.

Leão, A. A. P. (1944). J. Neurophysiol., 7, 359.

Lennox, M. A. (1947). Res. Publ. Ass. nerv. ment. Dis., 26, 342.

Lennox, W. G. (1946). Science and Seizures, 2nd ed. Harper, New York and London.

Liveing, E. (1873). On Megrim, Sick-Headache, and some Allied Disorders. Churchill, London.

Milner, P. M. (1958). Electroenceph. clin. Neurophysiol., 10, 705.

Ostfeld, A. M., Reis, D. J., and Wolff, H. G. (1957). A.M.A. Arch. Neurol. Psychiat., 77, 113.

Schwartz, M. (1953). In Clinical Genetics, pp. 551-557, ed. Arnold Sorsby. Butterworth, London.

Smith, C. H. (1937). J. Pediat., 10, 719.

Smith, R. E. (1951). Proc. roy. soc. Med., 44, 723.

Ulett, G. A., Evans, D., and O'Leary, J. L. (1952). Electroenceph. clin. Neurophysiol., 4, 463.

Vahlquist, B., and Hackzeli, G. (1949). Acta paediat. (Uppsala), 38,622 .

Vallery-Radot, P. (1955). Int. Arch. Allergy, 7, 323.

Wilson, S. A. Kinnier (1940). Neurology. Arnold, London.

Wolff. H. G. (1948). Headache and other Head Pain. Oxford University Press, New York.

(1955). Int. Arch. Allergy, 7, 210. 